Submission ID: 43897

\title{
Interpretation of IP-Affected 3D TEM Data
}

S.V. Kompaniets* (CJSC Irkutsk Electroprospecting Company), N.O. Kozhevnikov (Insitute of petroleum geology and geophysics SB RAS), E.V. Murzina (CJSC Irkutsk Electroprospecting Company)

\section{SUMMARY}

The TEM method is of broad use in oil and gas exploration in southern Siberian Craton, with about ten thousand soundings acquired yearly. The multi-offset TEM systems with $500-600 \mathrm{~m}$ square loops, which have been in use recently, can reveal also induced polarization (IP). IP-affected TEM data make about $75 \%$ of the total amount of transient responses recorded in the area. The IP effects can be estimated qualitatively from difference between the right-hand branches of apparent resistivity curves obtained with in-loop and off-loop configurations.

Processing of these data consists of several steps. First, TEM responses at reference points within the study area are inverted in a semi-automatic mode with IP effects included in terms of the Cole-Cole model. The polarization parameters of the resulting reference models are interpolated over the whole area with regard to difference between in-loop and off-loop responses. The equivalence is reduced by locking two out of four Cole-Cole parameters (most often $\mathrm{c}$ and $\mathrm{T}$ ). 
Интерпретация данных 3D ЗСБ с учетом параметров индукционно-вызванной поляризации

Компаниец С.В.*, Кожевников Н.О., Мурзина Е.В.

Введение

Метод зондирований становлением поля в ближней зоне (ЗСБ) широко используется при поисках нефти и газа на юге Сибирской платформы. В среднем ежегодно производиться около десяти тысяч зондирований. В последнее время используются многоразносные установки с генераторной петлей, длина стороны которой составляет $500-600$ м. Применение таких установок позволяет диагностировать эффект индукционно-вызванной поляризации (ВПИ) и проводить инверсию данных ЗСБ с его учетом (Кожевников, Компаниец, 2013). Влиянию индукционно-вызванной поляризации подвержены около 75 \% из общего числа индукционных переходных характеристик. Расхождение между левыми ветвями кривых кажущегося удельного сопротивления, измеренных соосной и разнесенными установками, позволяет оценивать проявления ВПИ на качественном уровне, а существующие математические алгоритмы на основе формулы Cole-Cole проводить инверсию кривых ЗСБ с учетом параметров ВПИ.

\section{Методика работ ЗСБ}

Регистрация данных ЗСБ производиться с помощью многоразносной установки. Размер источника поля (генераторная петля) составлял 600×600 м. Приемные датчики расположены на 6 разносах (расстояние от центра генераторной петли до центра приемной): 140 м (внутри петли), 510 м и 900 м. Выбор параметров установки обусловлен с одной стороны необходимой глубинностью исследований - 2 - 3 км, с другой - существующей $3 \mathrm{D}$ сетью сейсмопрофилей $200 \times 200$ м, относительно которой размещались источник и приемники поля.

При площадных наблюдениях изучаемый контур заполняется наблюдениями по равномерной сети. В представленной схеме шаг по профилю составляет 400 м, расстояние между профилями 200 м. Время регистрации сигналов становления составляет от 0.03 - 500 мс. Максимальный ток в петле достигает 170 А. Так, по методике площадных наблюдений изучен участок площадью в 350 кв.км.

Кривые ЗСБ, полученные на участке исследования, подвержены влиянию ВПИ. Визуально это выглядит (и подтверждается математическим моделированием) как расхождение кривых на поздних временах зондирования (как правило, на временах более 40 мс), полученных внутри генераторной петли и на разносах.

\section{D инверсия с учетом параметров ВПИ}

Учёт поляризуемости среды осуществлялся путём использования комплексного, зависящего от частоты удельного электрического сопротивления $\rho *(\omega)$, описываемого формулой Cole-Cole [Pelton at all, 1978]:

$$
\rho *(\omega)=\rho_{0}\left\{1-\eta\left[1-\frac{1}{1+(j \omega \tau)^{c}}\right]\right\}
$$

где $\mathrm{j}=\sqrt{-1} ; \omega$ - круговая частота, рад/c; $\rho 0$ - удельное сопротивление на постоянном токе, Ом·м; $\eta$ - поляризуемость, с - показатель степени $(0<\mathrm{c} \leq 1) ; \tau-$ время релаксации, с. Диапазон возможных значений параметра $\eta$ - от нуля до единицы, $\tau$ - от нуля до бесконечности.

Математическое моделирование и практика интерпретации показывают, что наиболее чувствительной к ВП является установка внутри петли, поскольку приемный датчик расположен наиболее близко к источнику возбуждения процессов ВП. Увеличение расстояния между источником и приемником поля приводит к ослаблению сигналов ВПИ, тем большему, чем ближе к поверхности расположен поляризованный объект. Так, при расположении зоны 
ВП в первом проводящем горизонте с ростом разноса от 0 до 1000 м сигнал ВПИ убывает более чем на 2 - 3 порядка. Важно отметить, что влияние ВПИ наиболее отчетливо наблюдается на поздних временах.

Данный факт является основой для схемы индивидуальной инверсии кривых ЗСБ (в рамках одной установки). В данном случае подбор модели в рамках сопротивления производится сначала для разнесенных кривых, затем переноситься на соосные кривые и далее подбираются параметры ВПИ до достижения минимальной невязки между практической и теоретической кривыми. Время релаксации не превышает временной интервал измерения переходных характеристик и, как правило, составляет $0.1-0.2 \mathrm{c}$.

При площадных наблюдениях количество получаемых данных значительно увеличивается по сравнению с профильными работами. Поскольку возможности трехмерной инверсии с учетом ВПИ технически ограничены, разработан альтернативный способ одномерной инверсии данных площадных съемок ЗСБ с учетом параметров поляризуемости. Он включает в себя несколько основных этапов:

1. Анализ параметра расхождения ветвей $(\Delta \mathrm{S})$ кривых ЗСБ, записанных внутри петли и на разносах, который помогает определить степень влияния ВПИ на качественном уровне:

$(1.2) \Delta \mathrm{S}=\frac{S(\mathrm{H})-S_{\mathrm{p}}}{S_{\mathrm{p}}} \times 100 \%$,

где $S(\mathrm{H})$ - значение проводимости на глубине Н по трансформации $S_{\tau}\left(H_{\tau}\right)$, полученное на соосных кривых, ${ }^{S}$ - среднее значение проводимости для разнесенных установок. (Гусейнов, 2015).

2.Подбор опорных моделей. При интерпретации данных площадных съемок методом ЗСБ выбираются опорные точки, на которых зарегистрированные кривые имеют одинаковый тип и характеризуют определенную геоэлектрическую зону, производится инверсия переходных характеристик с учетом ВПИ (на основе модели Коул-Коул). В результате формируются опорные модели с учетом параметров поляризуемости.

3. Определение зависимости $\Delta S$ от поляризуемости ๆ. Для этого используются опорные геоэлектрические модели, сформированные на этапе 2. Для каждой модели изменяется значение $\eta$ с заданным шагом и решается прямая задача. При этом время релаксации $\tau$ и параметр с закрепляются. По полученным кривым кажущейся проводимости вычисляется $\Delta \mathrm{S}$. Так полученная зависимость характерна для определенной геоэлектрической зоны

4. Вычисление $\eta$ с использованием полученной на этапе 3 зависимости $\Delta \mathrm{S}(\eta)$ и фактическое значение $\Delta \mathrm{S}$.

5. Модель поляризуемости распространяется по площади путем интерполяции на точки, где выявлено влияние ВПИ.

6. После подбора сопротивления, производиться анализ невязки и корректировка моделей.

Подбор геоэлектрических моделей на этапе формирования опорных моделей и в дальнейшей инверсии проводится с помощью программ MODEL 3 и 4 (Суров Л.В., Емельянов В.С., Поспеев А.В.), математическую основу которой образуют программные модули для решения прямой и обратной задач метода ЗСБ с учетом ВПИ (Каминский А.Е.).

Работа аппарата автоматической инверсии основана на методе Монте-Карло с элементами имитации отжига. Преимущество избранного алгоритма в его устойчивости к овражным поверхностям функции минимизации. Кроме того, методика интерпретации данных ЗСБ предполагает фиксацию геометрической части моделей - структурного каркаса, исходя из известных сейсмических поверхностей. Таким образом, подбираемыми параметрами модели остаются УЭС слоев и их поляризуемость. Для снижения эквивалентности решений были предприняты меры регуляризации функционала минимизации и сокращения области значений искомых параметров. В процессе инверсии для каждого искомого параметра находится значение, при котором достигается минимум невязки.

Результирующие модели описываются мощностями, продольным удельным электрическим сопротивлением и параметрами поляризации слоев. 


\section{Результаты работ}

Изучаемый участок работ находиться в пределах юга Сибирской платформы, в восточной части Непско-Ботуобинской антеклизы, в пределах Непского свода. Разрез осадочной толщи подразделяется на три крупных геоэлектрических комплекса: надсолевой относительно повышенной электропроводности, солевой - пониженной и подсолевой повышенной электропроводности, а также кристаллический фундамент. Всего в разрезе выделяются 8 - 12 основных геоэлектрических горизонтов.

На исследуемой площади общий объём наблюдений составил 4482 точки ЗСБ. Участок отличается сложным тектоническим строением, а также присутствием в разрезе траппов триасового возраста. Поэтому можно было бы предположить, что расхождения переходных характеристик, измеренных соосной и разнесёнными установками, связаны с влиянием неоднородностей. Однако с учётом того, что эти расхождения имеют площадное распространение, причём переходные характеристики, измеренные при одном и том же разносе, совпадают, с большей вероятностью отмеченные эффекты могут быть отнесены на счёт ВПИ.
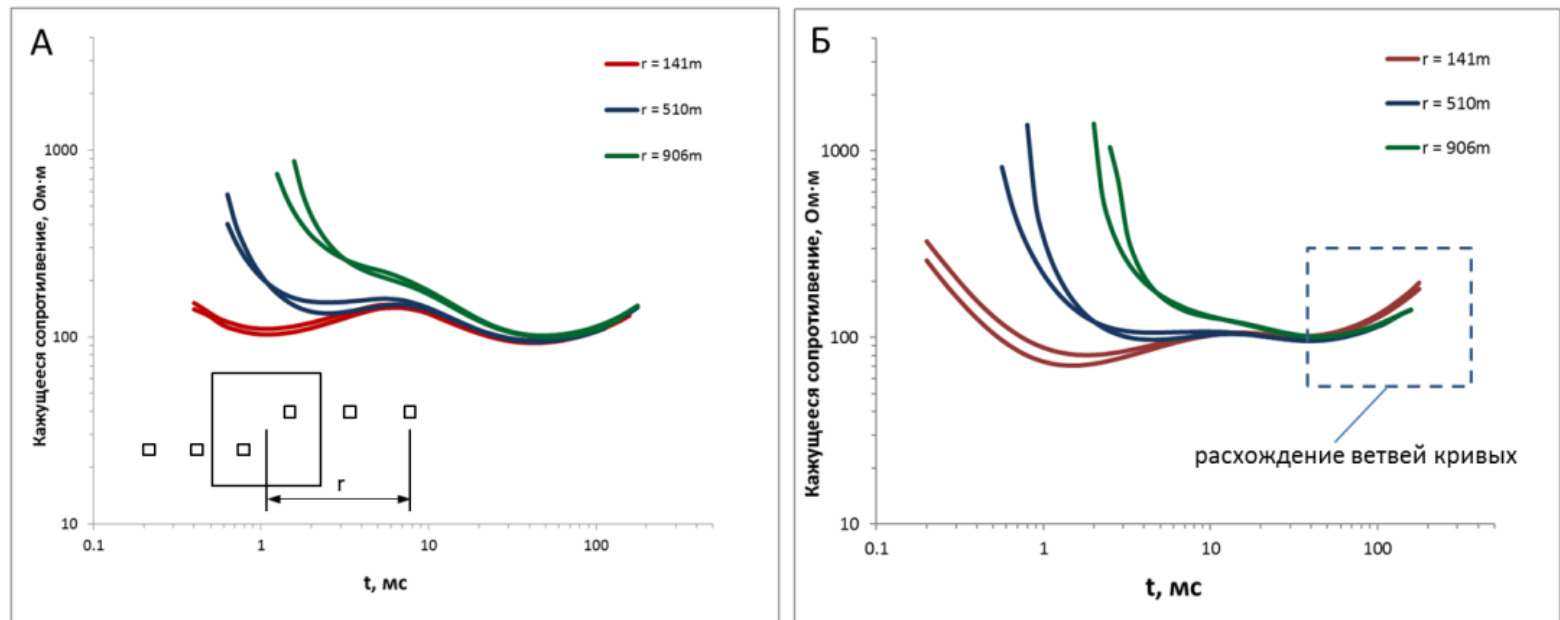

Рисунок 1 Кривые кажущегося сопротивления: А - без ВП, Б - с ВП, зарегистрированные 8 пределах одного участка.

По данным описания керна водозаборных скважин, находящихся на несколько километров южнее от изучаемого участка, в породах усть-кутской свиты юры и верхней части верхоленской и илгинской свит кембрия отмечено присутствие кристаллов и прожилков пирита, до 3 см (в интервале от 0 до 60 м). Также имеются пропластки каменного угля и углистых аргиллитов, с которыми могут быть связаны проявления вызванной поляризации. Связь повышенной поляризуемости и юрских отложений подтверждает сравнение карт поляризуемости и контура распространения юрских пород.

По результатам инверсии значения поляризуемости составляют $0.01-0.15$. Повышение коэффициента наблюдается в основном в юго-восточной части площади время релаксации $\tau$ и степенной коэффициент $\mathrm{C}$ закреплялись на уровне, обеспечивающем минимальную суммарную невязку всего массива данных в пределах зон с выраженным проявлением эффекта ВПИ $(\tau=0.1 \mathrm{c}, \mathrm{C}=0.6)$. Представляется, что свойства пород, которые характеризуются данными параметрами, малоизменчивы. 


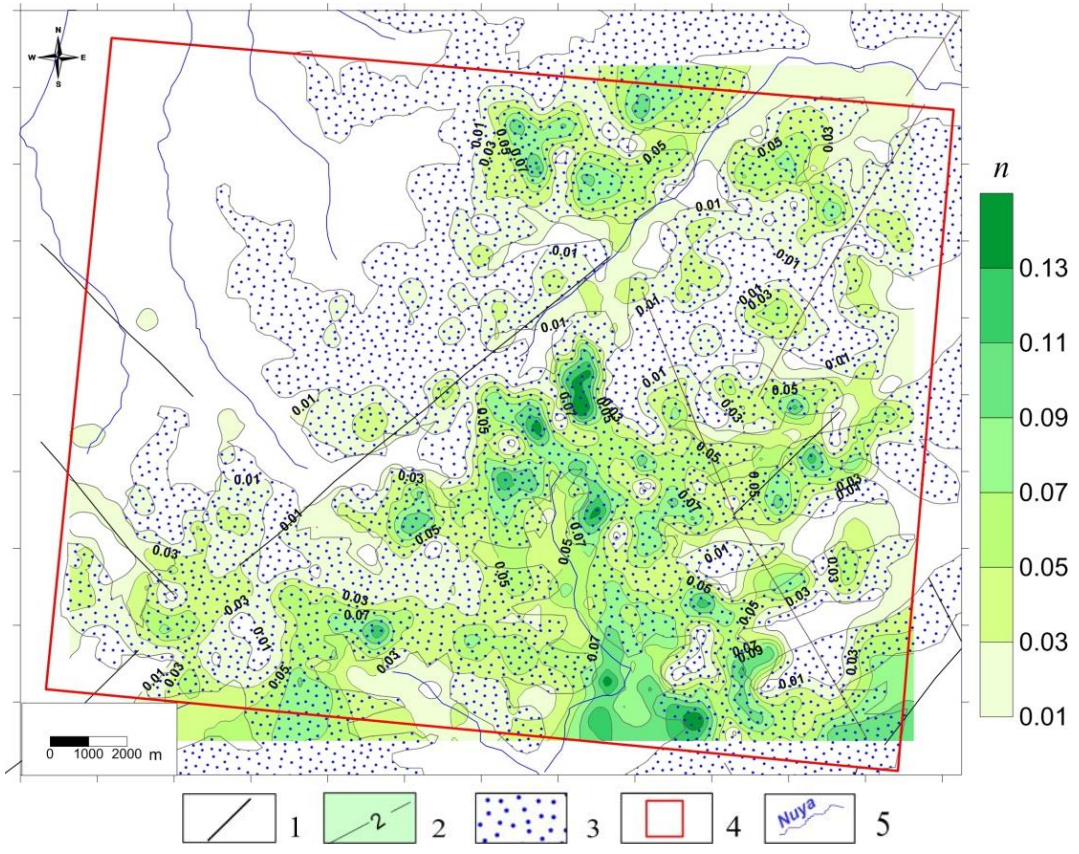

Рисунок 2 Карта поляризуемости и распространения юрских пород

Условные обозначения: 1 - тектонические нарушения по данным геологической карты масштаба 1:200000, 2 - изолиния поляризуемости, 3 - отложения юры по данным геологической карты, 4 - контур участка работ, 5 - гидросеть.

\section{Выводы}

Качественный анализ проявления ВПИ и расчет параметра $\Delta S$, характеризующего расхождение правых ветвей кривых ЗСБ (полученных на различных разносах) позволяет экспрессно оценить распространение поляризующихся пород на площади и создать первичную/априорную модель поляризуемости, используемую для дальнейшей инверсии. Данная процедура значительно сокращает время на инверсию массовых данных.

Учёт эффектов ВПИ при проведении инверсии данных ЗСБ, полученных с многоразносной установкой, приводит к существенному повышению точности оценки сопротивления геоэлектрических горизонтов разреза.

Согласно результатам инверсии данных ЗСБ на основе модели среды, удельное сопротивление которой описывается формулой Коул-Коул, проявления ВПИ связаны с породами верхней части разреза с параметрами: $\rho=25-80 \mathrm{Oм} \cdot \mathrm{M}, \eta=0.01-15, \tau=0.1 \mathrm{мc}, c=0.6$.

В результате сопоставления полученного в ходе инверсии распределения поляризуемости и геологической карты участка работ природа явления предположительно связывается с присутствием пирита в отложениях юры и верхнего кембрия.

При анализе кривых ЗСБ, полученных на исследуемом участке, необходимо выявлять данные, осложненные влиянием геоэлектрических неоднородностей, поскольку интерпретация таких материалов будет иметь ошибочный результат.

\section{Библиография}

Антонов Е.Ю., Кожевников Н.О., Компаниец С.В. Проявление и учет индукционно-вызванной поляризации при изучении осадочного чехла юга Сибирской платформы методом ЗСБ. «Геофизика», №2, 2013, М., ЕАГО, с.35 - 40.

Геология нефти и газа Сибирской платформы. Под ред. А.Э. Конторовича, В.С. Суркова, А.А. Трофимука. // М.: «Недра». - 1981. - 552 с. 


\section{EAGE}

\section{References}

Antonov E.Yu., Kozhevnikov N.O., Kompanietc S.V. [2013] The manifestation and account of induction-induced polarization in the study of the sedimentary cover of the south of the Siberian platform by the TEM.”Geophysica", 2, 35-40.

Kontorovich A.E., Surkov V.S., Trofimuk A.A. [1981] Geology of oil and gas of the Siberian platform. 552. 